\title{
Netflix Addiction- A Life Hacker: Short Communication
}

\author{
Harshitha
}

MSc Nursing, Psychiatric Nursing Department, RV College of Nursing Bangalore

\begin{abstract}
Internet addiction is a behavioural addiction, similar to compulsive gambling, that can lead to behaviours similar to those seen in drug abuse disorders, such as bingeing. If we are not careful, internet and Netflix addiction might have a negative impact on our mental and physical health. Anxiety, depression, and loneliness can all be exacerbated by bingewatching. Any addiction requires the development of self-control and lifestyle changes that may provide a significant amount of diversion.

The National Institute of Mental Health and Neurosciences (NIMHANS) in Bengaluru has received the country's first case of Netflix addiction. Researchers have discovered instances when people's addiction has affected their interpersonal connections and caused them to lose productivity at work. The possibility of including Internet Addiction Illness as a diagnosable condition in the clinical setting has been investigated.

Meditation and other alternative activities, such as sports or nature walks, should be encouraged; finding a good balance is essential for overall wellness. There hasn't been a lot of research on how binge-watching affects mental health because it's a relatively new phenomena that's only been around for around five years.
\end{abstract}

Key words: Internet addiction, Binge-Watching, Anxiety, Depression, and Loneliness

\section{INTRODUCTION}

Internet addiction is a behavioural addiction, like compulsive gambling, and can result in behaviours, such as bingeing, that are like those found in substance abuse disorders. $^{[1]}$ Internet and Internet and
Netflix addiction can have a serious impact on your mental and physical health if we are not careful.

Entertainment has long been a source of escapism, but streaming services that make a whole season of a show available to watch on computers, smartphones, tablets, and other devices have increased the likelihood of binge-watching. It's becoming more usual for consumers to binge-watch a complete season of their favourite thriller in a single sitting. But what if you are unable to stop? How much time do you spend on the couch binge-viewing movies and watching episodes on video-ondemand platforms and streaming services?

$$
\text { Researchers have found }
$$
circumstances when people's addiction has caused them to lose productivity at work and has harmed their interpersonal relationships. The National Institute of Mental Health and Neurosciences (NIMHANS) at Bengaluru's Service for Healthy Use of Technology (SHUT) clinic received its first case: A 26-year-old guy who is unemployed for more than six months, used Netflix to escape reality. ${ }^{[4]}$

The COVID-19 outbreak resulted in a huge rise of $27 \%$ in time spent on media consumption around the world. Videostreaming companies, often known as overthe-top (OTT) platforms, are competing for our attention. Netflix, Amazon Prime, Hotstar, Sony Liv, Zee5, Voot, Eros Now, ALT Balaji, MX Player, and other streaming services have grown quite popular among young people. 


\section{Netflix Addiction in India}

In Bengaluru, the National Institute of Mental Health and Neurosciences (NIMHANS) got the country's first case of Netflix addiction. Manoj Kumar Sharma, professor of clinical psychology at NIMHANS and director of the SHUT clinic, said the man began binge-watching films and episodes on Netflix for more than seven hours a day because it made him feel better."Whenever his family pressed him to work or he saw his peers succeeding, he would binge-watch the available episodes. It was a way of getting away from it all. Dr. Sharma added, "He could forget about his difficulties and get a lot of pleasure out of it."

The first thing he did when he awoke was turn on the television. The joy, however, was temporary, as the young guy discovered that he was unable to exercise any type of self-control. It caused eye strain, fatigue, and sleep disturbances. Doctors at the facility are addressing his psychological concerns through treatment, providing relaxation techniques, and mentoring him in his profession to help him overcome his addiction.

\section{What are the signs and symptoms of 'Netflix addiction'?}

Preoccupied mind: A constant stream of inquisitive ideas about "what will happen next" that leads to binge-watching.

Irresistible urge: "Just one more episode" is a typical bargaining chip, indicating an unwillingness to stop binge-watching even if you really want to.

Inability to sleep: The habit of staying up late watching TV shows, losing sleep, and then being wide awake.

Streaming everywhere: Individuals may watch episodes while travelling, using the restroom, working, cooking, or even driving.

Some people consider Netflix to be their best friend or first love.

Binge-watching and not realising they've reached the final episode.
Go straight from one episode to the next without pausing.

Without pausing, jump from one episode to the next.

They keep watching the same shows and movies over and over again.

Check the home page frequently to check if any new series or movies have been added.

They haven't been out of bed in three days.

They haven't bathed or brushed their teeth in a few days and haven't changed their clothes.

Their eyes have turned crimson.

They experience bodily discomfort when they are not binge-watching at home.

They cry over fictional characters more than they do in real life or when seasons of their favourite show get added.

All of their devices have Netflix.

Netflix is undoubtedly their most popular website. ${ }^{[5]}$

\section{Effects of Netflix Addiction on Health}

When the body is exposed to acute stress, such as not knowing what will happen next, it creates an excess of $\mathrm{CRH}$, a hormone that regulates the release of other stress hormones. This keeps the body active (our fight or flight reaction), which might make it difficult to sleep.

When we reach a new level of Netflix skill, we're actually activating the reward region of our brains. We feel as if we have completed a task when we finish a number of episodes or perhaps an entire series, which generates a surge of dopamine release in our brains. This dopamine then urges us to keep watching, producing a seemingly never-ending feedback cycle.

The release of dopamine and motivation is a characteristic of addiction, so could we become addicted to Netflix? Many of us joke about being "addicted" to our favourite shows, but for someone else, this attitude could imply something lot more serious. Since 1996, Internet Addiction Illness has been examined and considered for inclusion as a diagnosable disorder in the clinical environment. 
Interpersonal issues: Constant issues and even fights with parents or spouses, usually over the amount of time spent on OTT platforms.

Procrastination, messed-up to-do lists, missed deadlines, and poor work or academic performance all limit productivity.

Sleepless nights: Sleepless nights that occur on a regular basis in order to finish an episode or a series.

Increased hatred or rage as a result of the series' content, as well as other psychological issues

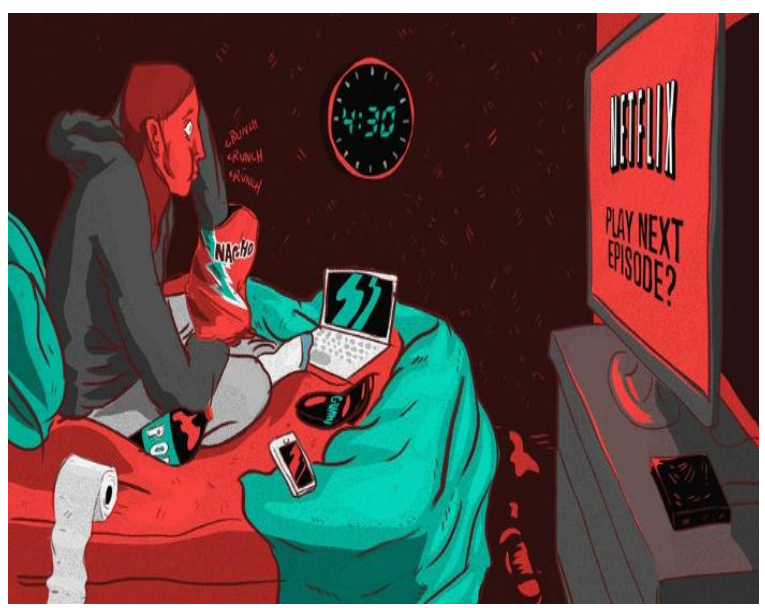

\section{MENTAL HEALTH CONSEQUENCES OF NETFLIX ADDICTION}

Binge-Watching has the potential to Increase Anxiety, Depression, and Loneliness.

Since binge-watching is a relatively new phenomenon, ballooning over the past five years or so, there hasn't been a lot of research into how it affects mental health ${ }^{[2]}$. One study by researchers from the University of Texas at Austin found a high correlation between binge-watching, depression and other studies have found negative effects including increased fatigue, mood disturbances, and insomnia.

- Binge-watching can make It Difficult to Sleep

The state of "pre-sleep arousal" appears to be important as well. Biological and psychological factors contribute to presleep arousal. A number of studies have discovered that intense screen light, particularly in the blue spectrum, mimics daylight biologically.

When a person is exposed to this type of light before night, their circadian cycle may be disrupted, making sleeping more difficult. A show may psychologically agitate them, sometimes for hours, when they should be winding down for sleep. Good TV shows provide drama, excitement, suspense, and action, but they also increase their heart rate, blood pressure, and adrenaline levels. When they eventually get to bed, they may feel stressed or even mildly traumatised, which is not conducive to sleep.

This sleep deprivation might have a negative impact on mental health. A persistent sleep deprivation has been shown in several studies to quickly impair mental abilities such as attention, working memory, and emotional regulation. Insomnia has been related to an increased risk of serious depression and anxiety disorders in the long run.

- Binge-watching reduces physical activity.

The fact that binge-watching carries a significant opportunity cost is maybe the most serious issue with it. That is, every hour you spend watching television is an hour you are not doing anything else, including moving. This has a negative impact on your mental and physical wellbeing. Obesity and related illnesses such as diabetes and heart disease can be exacerbated by excessive sitting and munching. According to recent studies, obesity increases the risk of depression and vice versa

- We have a tendency to binge-watch alone.

Binge-watching isn't simply a sign of loneliness; it can also make you less likely to accept invitations, seek out to friends, or even leave the house, all of which contribute to loneliness. It's worth mentioning, too, that many people bingewatch for social reasons. In other words, they want to be able to discuss a show with their friends or co-workers. To put it another 
way, people want to be able to discuss a show with their friends or co-workers.

When a show is over, it can be disappointing.

Finally, while binge-watching a television may make an individual feel better; it will finally come to an end, leaving the individual feeling disappointed. At some level, consider TV characters as if they were actual friends and acquaintances, and miss them when they leave. Invest in the storylines' significance, the show's exciting events, and the fascinating universes in which it all takes place. When it's all over, they're left with a dull reality, which doesn't enhance their mood. .

Binging is harmful for us, whether it's from alcohol, cake, or even good television. Furthermore, bingeing has become a problem partly as a result of behavioural manipulation by the media. It is in your best interests to choose how you spend your time and to do it in a way that promotes your health and pleasure. It is in our best interests to choose how you spend your time and to do it in a way that promotes our health and wellbeing. ${ }^{[7]}$

\section{Other hazardous health consequences due to binge-watching impacting physical health}

Watching a lot of television raises the risk of obesity by $23 \%$ another reason for the increased risk of weight gain is that watching series for a long time is often linked to the consumption of unhealthy food, implying that people are more likely to consume food that is high in fat and carbohydrates

The increased risk of type 2 diabetes, fatal or non-fatal cardiovascular disease and all-cause mortality has also been shown to be consistently related to a longer span of TV viewing time

\section{Binge-watching during the era of COVID-19}

This year was challenging, and for many of us, it was one of the most difficult we've ever experienced. Overall, this year was unlike any other, with considerable increases in stream times due to lockdowns and social isolation. During the COVID-19 lockdown phase, people of all ages around the world are experiencing anxiety and mental breakdown.

As people suffer days of loneliness at home, such a condition gives the ideal setting for playing online games and watching television. As leisure outlets, inhome environments are limited, whereas the internet/TV is freely accessible, readily available, and, of course, economical; this can lead to binge-watching.

People all throughout the world began to concentrate on the readily accessible means of entertainment in their home settings as the sources of amusement and social interaction reduced during the pandemic.

According to an online survey of the general public in four Southeast Asian nations (Bangladesh, India, Indonesia, and Nepal), there is a significant increase in binge-watching during the lockdown period, with an average time of 3-5 hours and 5+ hours of binge-watching. This study also found that binge-watching frequently disrupts sleep, interferes with work completion, and generates interpersonal difficulties. ${ }^{[8]}$

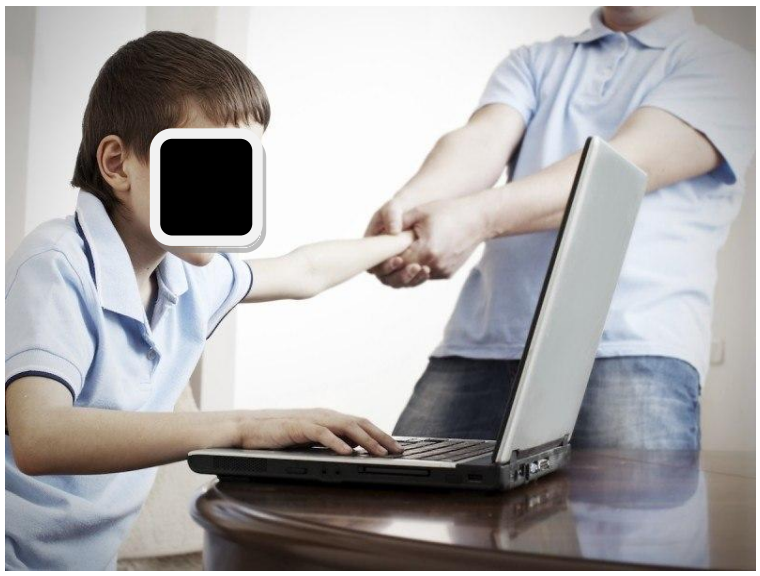

\section{What happens to all those hours?}

Every month, Netflix customers watch over 2 billion hours of movies and television episodes! Netflix has the potential to cause havoc on time management. But why is that? The chunking principle 
describes how the human brain receives, processes, and remembers information in little chunks. This includes how we handle time. We find it much easier to divide our time into manageable chunks, such as 30 minutes or 60 minutes. However, most Netflix shows are 40 minutes or 20 minutes long, which does not quite fit into our allotted time slots. Because light plays such an important role in the control of sleepwake cycles, we've surely heard that too much light from a TV screen or laptop might keep people up late at night.

\section{How do you keep your Netflix "addiction" under control?}

Managing any addiction necessitates the development of self-control and lifestyle modifications that might provide a great amount of diversion.

Meditation and other alternative interests, such as sports or nature walks, should be encouraged; achieving a good balance is crucial for a healthy existence in general.

\section{How to Deal With \\ Individual or group counselling sessions are available.}

Counselling sessions can be very beneficial in overcoming addictions. Addictions are complicated but treatable; nevertheless, it is critical to attend sessions on a regular basis. The most effective treatment for behavioural addictions is cognitive-behavioural therapy.

\section{Recognize that there is a problem}

Make a note of how many hours a person spends on OTT platforms. Count the amount of times people have gotten into fights over binge-watching shows. And the number of times they were pushed to finish 'just one more episode'.

\section{Replace it with something healthy.}

Consider what a person could be doing if they weren't binge-watching. Individuals may participate in creative activities, skill-building activities, or even self-care activities. Returning to a childhood activity, keeping a journal, meditating, reading books or novels, and spending time with family are all good substitutes.

\section{Clear all the clutter}

It is recommended to follow the 'out of sight, out of mind' philosophy, just as it is for any other addiction. Start by removing any applications that are taking up too much of your time. You can also unsubscribe from their mailing list.

\section{Reward for each episode}

A person might schedule his or her day according to the vital and urgent tasks that must be completed. He can reward himself with a new episode of his favourite TV once he's finished with those. This will keep him motivated and help him prioritise his tasks.

One must understand that no single treatment can work for everyone. Connecting with a mental health expert can help you overcome this addiction ${ }^{[6]}$.

\section{Regular exercises}

Perhaps more importantly, taking regular exercise is an important part of a comprehensive therapy strategy for patients who have a history of depression or anxiety. Exercise has been shown in numerous studies to boost mood by increasing levels of endorphins, serotonin, and BDNF, a neurotransmitter that promotes the growth of neurons in certain areas of the brain. Exercise causes structural changes in the brain that make learning new things easier. Exercise also affects the structure of the brain, making you less susceptible to stress and anxiety.

\section{CONCLUSION}

Netflix has become the new opium of the people, with many individuals becoming addicted to it. However, bingewatching shows on video-on-demand platforms and streaming services such as Netflix may be fatal; having a negative effect on your health, social life, emotions, and more. Sitting for prolonged periods has been related to an increased risk of heart 
disease, diabetes, obesity, cancer, and other health problems. As a result, it may be concluded that watching back-to-back episodes of the same show stimulates the brain and, as a result, interferes with sleep. Depression and anxiety, spinal difficulties, a lack of oxygen, a lack of physical activity, and a larger waistline are some of the other negative health repercussions. These side effects are the most common causes of heart disease and stroke. According to current findings, limiting binge behaviour may be advantageous to individuals and may also help to prevent the development of lifestylerelated problems.

\section{Acknowledgement: None}

\section{Conflict of Interest: None}

\section{Source of Funding: None}

\section{REFERENCES}

1. R.Sreevani "A Guide To Mental Health \& Psychiatric Nursing", Jaypee Brothers Publishers, Third Edition, 2010, Pg.No.192206.

2. KP Neeraja "Essentials of Mental Health and Psychiatric Nursing", Volume 2, Jaypee Brothers Publishers, First Edition, 2008,Pg. No. 593-616.

3. Professor G.Hussein Rassool "Addiction for Nurses" Wiley-Blackwell publisher, First edition, 2011, Pg. No. 172-186.
4. https://www.thehindu.com/news/cities/bang alore/nimhans-clinic-treats-first-case-ofnetflix-addiction/article25151600.ece

5. https://www.usatoday.com/story/tech/nation -now/2018/10/08/netflix-addiction-treatedindian-clinics-first-case-reportsays/1566447002/

6. Binge-Watching: Signs You Have A TV Addiction And How To Cure It. MissMalini [Internet]. [cited 2021 Jun 21]; Available from:

https://www.missmalini.com/2021/01/06/bi nge-watching-signs-you-have-a-tvaddiction-and-how-to-cure-it/

7. How Does Binge-Watching Affect Your Mental Health? [Internet]. [cited 2021 Jun 21]. Available from: https://www.forgingnewlives.com/blogposts/how-does-binge-watching-affect-yourmental-health

8. Binge-watching: Impacting mental and physical health [Internet]. Countercurrents. 2020 [cited 2021 Jun 21]. Available from: https://countercurrents.org/2020/11/bingewatching-impacting-mental-and-physicalhealth/

How to cite this article: Harshitha. Netflix addiction- a life hacker: short communication. International Journal of Science \& Healthcare Research. 2021; 6(3): 395-400. DOI: https:// doi.org/10.52403/ijshr.20210765 